\title{
An Information System Audit Model for Project Quality Improvement by the Agile Methodology
}

\author{
Dong Hyup Kim, Dong Soo Kim, Chan Koh, and Hee Wan Kim
}

\begin{abstract}
Software development has been applied with various automatized tools and techniques to increase the productivity in order to supply the requested products on time with the highest quality to customers. As a result, numerous software development methodologies have been tried continuously during the practical work. As a consequence of this effort, an agile methodology has recently been utilized in many projects in order to promptly deal with changing demands of customers. In the case of South Korea, project-applicable methodologies have been established and applied to different fields, and this tends to expand further.

Information system audit evaluated product suitability throughout the whole development process including the previous step and contributed greatly to the quality enhancement. However, there are several differences between recently growing agile project and the previous one, such as management methods, construction phases, and key products. As a result, information system audit should understand the character of agile and review the comprehensive development process.

This paper proposes an audit model that is suitable to the agile project by comparative analysis between the current audit model and agile methodology. Agile methodology audit model will be advantageous to the Agile applied project audit. The model should be verified and supplemented by applying to the practice, and various Agile practical items should be applied continuously and studied further.
\end{abstract}

Index Terms-Agile methodology, information system audit, audit model style, agile audit model.

\section{INTRODUCTION}

There has been rapid growth and progress in numerous development methodologies to model information system. To draw or model the information system as a communication tool within a term or with the customer, the model will need the methodology or method that can be used as an explicit way to think and act [1]. For some writers, methodology is different from method [2]. A methodology or software engineering method consists of process, standard vocabulary, set of rules and guidelines which tell what to do, how to do, when to do and why it is done [1], [3]. Agile methodology as an evolutionary development will more effectively meet the needs of the customer quickly,

Manuscript received November 20, 2012; revised March 18, 2013.

Dong Hyup Kim is with the Samsung SDS, Seoul, 135878 Korea (e-mail: hyupdong.kim@samsung.com).

Dong Soo Kim is with the Graduate School of Information System, Konkuk University, Seoul, 143701 Korea (e-mail: dskim@kisac.co.kr).

Chan $\mathrm{KOH}$ is with the Department of Computer Science and Engineering, Seoul National University of Science and Technology, Seoul, 139743 (e-mail: chankoh@seoultech.ac.kr).

Hee Wan Kim is with the Division of Computer Science and Engineering , Shamyook University, Seoul, 143742 Korea (e-mail: hwkim@syu.ac.kr). adaptively and focus on the software itself. In the beginning, agile methodology was suitable for small- or medium-sized business and personal computer products [3], but soon this has been implemented in large-sized business as well [4]. A primary methodology, which is similar to "coding, modification, re-coding," became structured like a waterfall model. It was developed into standardized methodology, and many methodologies that control and administer software production were created and applied constantly [5]. An organization established methodologies that are suitable to their character, determined tools and outputs, and standardized them. Based on these, efforts were put on providing customer-requested products at the right time with high qualities. During the 21 st century, a new paradigm called the agile development methodology appeared and achieved good results by putting value on interaction among software developers, operating software, cooperation with customers, and coping with the change [6]. Most of development process goes through tailoring and is modified to be suitable for the project. The Agile methodology can be understood as reducing process. However, if Agile/agility is missing, reducing process cannot define the Agile methodology [7].

The application of the agile methodology to projects is limited so far. Projects run in a chaotic way in reality by overlapping with other development methodologies and management processes. On the other hand, there are few cases that advantages of Agile processes were not accepted by incomprehension of the agile process and maladaptation to the change. Problems and improvements in these instances should be detected so that the quality of the Agile applicable projects will be increased, and these improvements play a key role in information system audit. Most of the system development domain can be applied to the audit but the audit model, which checks Agile project management and development process comprehensively, is positively necessary. As a result, Agile methodology audit model should be studied so that Agile project audit will be more effective. This thesis proposes Agile methodology audit model by comparative analysis between Agile methodology and the current audit model.

\section{The Problems In THE CURRENT INFORMATION SySTEM AUDIT MODEL}

Business, which applies Agile to the Information system development, has currently been increasing but audit guidelines for Agile do not exist, and audit is performed by applying an object-oriented/component based model. The audit is stepwise including requirement definition, design, and termination. The business' size and risk of danger should 
be considered to determine if it is necessary to perform an additional audit or more auditors can be stationed at the field to audit. If working expenses is under two million dollars or duration of work is under six months, the requirement definition step can be omitted. In this case, the ordering body should check directly whether tasks in the requirement definition document are reflected or not [8].

TABLE I: AGILE ProcesS AND CURRENT AUdiT CRITERIA [8]-[12]

\begin{tabular}{|c|c|c|c|c|}
\hline \multicolumn{2}{|c|}{ Steps } & Activity/action & Product & $\begin{array}{l}\text { Current } \\
\text { audit } \\
\text { criteria }\end{array}$ \\
\hline \multirow{3}{*}{\multicolumn{2}{|c|}{ Requirement Definition }} & $\begin{array}{c}\text { Defining User } \\
\text { story }\end{array}$ & \begin{tabular}{|c|} 
User story, \\
Product backlog
\end{tabular} & $\mathrm{X}$ \\
\hline & & $\begin{array}{l}\text { Establishing test } \\
\text { plan }\end{array}$ & Test protocol & $\mathrm{O}$ \\
\hline & & $\begin{array}{l}\text { Defining } \\
\text { Architecture }\end{array}$ & $\begin{array}{c}\text { Architecture } \\
\text { definition } \\
\text { document }\end{array}$ & $\mathrm{O}$ \\
\hline \multicolumn{2}{|c|}{ Release planning } & \begin{tabular}{|c|} 
Establishing \\
release schedule
\end{tabular} & $\begin{array}{l}\text { Release } \\
\text { protocol }\end{array}$ & $\mathrm{X}$ \\
\hline \multirow{7}{*}{$\begin{array}{l}\text { Architecture/ } \\
\text { construction }\end{array}$} & Sprint launch & \begin{tabular}{|} 
Establishing sprint \\
plan
\end{tabular} & Sprint backlog & $\mathrm{X}$ \\
\hline & \multirow[t]{2}{*}{ Analysis/design } & $\begin{array}{l}\text { Constructing } \\
\text { Architecture }\end{array}$ & $\begin{array}{c}\text { Architecture } \\
\text { definition } \\
\text { document, } \\
\text { UI standard, } \\
\text { development } \\
\text { standard } \\
\end{array}$ & $\mathrm{O}$ \\
\hline & & $\begin{array}{c}\text { Application } \\
\text { analysis/design }\end{array}$ & $\begin{array}{l}\text { Monitor } \\
\text { definition } \\
\text { document } \\
\text { ERD }\end{array}$ & $\mathrm{O}$ \\
\hline & Development & $\begin{array}{l}\text { Application } \\
\text { development }\end{array}$ & Source code & $\mathrm{O}$ \\
\hline & Test & $\begin{array}{c}\text { Measure test } \\
\text { implement }\end{array}$ & $\begin{array}{l}\text { Test scenario, } \\
\text { result }\end{array}$ & $\mathrm{O}$ \\
\hline & \multirow{2}{*}{ Sprint Review } & Customer review & $\begin{array}{l}\text { Sprint review } \\
\text { (customer) } \\
\text { result }\end{array}$ & $\mathrm{X}$ \\
\hline & & Retrospect & $\begin{array}{l}\text { Retrospect } \\
\text { result }\end{array}$ & $\mathrm{X}$ \\
\hline \multirow{3}{*}{\multicolumn{2}{|c|}{ Examination }} & $\begin{array}{l}\text { Integrated test } \\
\text { implementation }\end{array}$ & $\begin{array}{l}\text { Integrated test } \\
\text { scenario, results }\end{array}$ & $\mathrm{O}$ \\
\hline & & $\begin{array}{c}\text { System test } \\
\text { implementation }\end{array}$ & \begin{tabular}{|c|} 
System test \\
scenario, results
\end{tabular} & $\mathrm{O}$ \\
\hline & & Acceptance test & $\begin{array}{c}\text { Acceptance test } \\
\text { results }\end{array}$ & $\mathrm{O}$ \\
\hline \multicolumn{2}{|c|}{ Execution } & Manual making & User manual & $\mathrm{O}$ \\
\hline \multicolumn{2}{|c|}{ Project launch } & Project planning & $\begin{array}{l}\text { Project plan, } \\
\text { WBS }\end{array}$ & $\mathrm{O}$ \\
\hline \multirow{3}{*}{\multicolumn{2}{|c|}{$\begin{array}{l}\text { Project performance } \\
\text { regulation }\end{array}$}} & $\begin{array}{l}\text { Requirements } \\
\text { alterations and } \\
\text { administration } \\
\text { (management) }\end{array}$ & $\begin{array}{c}\text { Product } \\
\text { backlog, } \\
\text { User story }\end{array}$ & $\mathrm{X}$ \\
\hline & & $\begin{array}{c}\text { Issues and danger } \\
\text { management }\end{array}$ & $\begin{array}{l}\text { List of issues } \\
\text { and risks }\end{array}$ & $\mathrm{O}$ \\
\hline & & $\begin{array}{c}\text { Progress } \\
\text { management }\end{array}$ & $\begin{array}{c}\text { User backlog, } \\
\text { Sprint backlog, } \\
\text { A burn-down } \\
\text { chart }\end{array}$ & $\mathrm{X}$ \\
\hline \multicolumn{2}{|c|}{ Project termination } & Project termination & $\begin{array}{c}\text { System } \\
\text { handover, final } \\
\text { exam } \\
\text { confirmation }\end{array}$ & $\mathrm{O}$ \\
\hline
\end{tabular}

However, Agile process proceeds in these steps: requirement definition $\rightarrow$ release plan $\rightarrow$ construction $\rightarrow$ test $\rightarrow$ execution. Since Agile methodology has its sprint cycle repeated many times depending on the release plan, there is much difference between the current audit and the audit with Agile methodology applied.

Since the audit domain is not a process by which the Agile process does not aim for a specific field or system, it is possible to apply equally the current audit domain. However, the company's change management such as active customer participation, culture, and organizational change during a frequently repeated Agile process is an important factor for the company that is accustomed to the existing development step. The current audit domain does not consider these change management, though.

The audit perspective/inspection standard is that a working process and its product are not equal according to an Agile development process. Therefore, the development environment and process should be understood and the audit viewpoints and standard should be applied accordingly.

The product backlog and sprint backlog, Agile's representative outputs, are similar to the requirement definition, but audit can be performed only when the product contents are comprehended thoroughly. However, relevant check points or detailed review factors are not considered in the current audit inspection framework.

Moreover, review factors that can guarantee the adequacy such as a burn-down chart, sprint review, and retrospect results, which represents project management and quality assurance document, are not considered. New methods should be sought to secure the visibility and traceability of the requirements, because Agile products are variant.

The Agile project process and main outputs, as well as the comparison with the current audit criteria are organized as below Table I.

\section{Proposal of Agile Methodology Audit Model}

\section{A. Agile Methodology Audit Model}

Agile methodology audit model reuses the current information system development audit model and combines important considerations adequately during the Agile methodology audit. The fact that audit of the Agile-based development project is processed effectively and the audit quality of the project can be enhanced is a great significance.

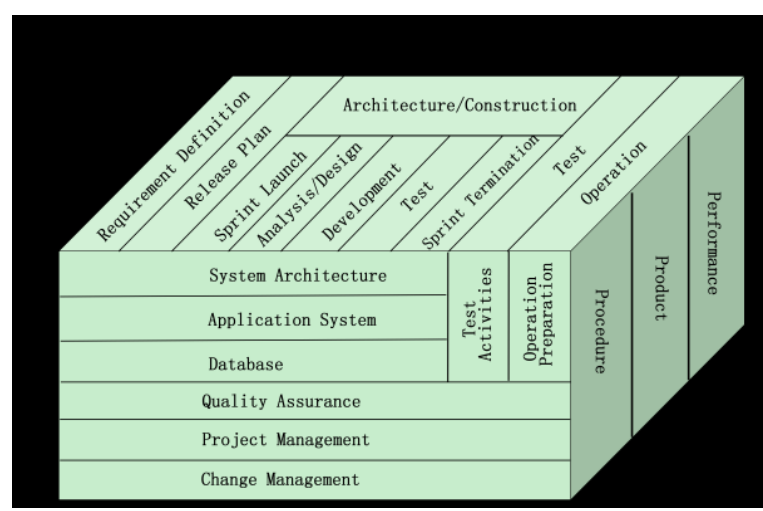

Fig. 1. Agile methodology audit model.

\section{1) Audit point}

The Agile process was applied to the audit point, which is composed of requirement definition, analysis/design, implementation, test, and operation steps of the current information system audit model. On the other hand, Agile methodology audit model consists of requirement definition, release plan, architecture/construction, test, and operation steps.

The release plan was added after requirement definition, especially because of iteration, which is a key component of Agile. Architecture/construction phase was repeated 
accordingly with the release plan. This phase was composed of sprint launch, analysis/design, development, test, and sprint termination. It was applied with frequent release and repetitive development process [11], [12].

The audit point of the current information system audit model and the Agile methodology audit model is illustrated in Table II.

Requirement definition phase has the user story as a foundation. Defining the requirements check whether the system scope is omitted or not. It also ranks priorities of the user story and computes story points. Moreover, it checks whether development plan, which is placed in each sprint, was established reasonably or not.

Release planning phase checks for the range of performance during the release and determine if schedule will proceed as planned. It also inspects whether the iteration period and complete schedule are defined or not.

Architecture/construction phase sets the sprint plan based on user story and architecture and verifies the possibility of developing and testing the code. Its inspection focuses on the completeness of the user story, which is assigned to the sprint by customer reviews

The test phase checks for whether integrated test, system test, and acceptance test are performed comprehensively. The implementation stage finally inspects for an appropriate termination of release-functional manual, education, transition, and examination.

TABLE II: Audit Time of the CurRent And Agile Methodology Audit Model [8], [11], [12]

\begin{tabular}{|c|c|c|c|c|c|c|c|c|c|}
\hline Classification & \multicolumn{9}{|c|}{ Audit Time } \\
\hline Current audit model & \multicolumn{2}{|c|}{ Requirement analysis } & \multicolumn{2}{|c|}{ Analysis/design } & \multicolumn{3}{|c|}{ Implementation } & Test & Operation \\
\hline \multirow{2}{*}{ Agile methodology audit model } & \multirow{2}{*}{ Requirement definition } & \multirow{2}{*}{ Release plan } & & Archit & /construct & & & \multirow{2}{*}{ Test } & \multirow{2}{*}{ Operation } \\
\hline & & & Sprint launch & $\begin{array}{l}\text { Analysis } \\
\text { /design }\end{array}$ & $\begin{array}{c}\text { Develop } \\
\text {-ment }\end{array}$ & Test & Sprint Review & & \\
\hline
\end{tabular}

TABLE III: CheCk List Deduced fRom the Domain of THE Change MANAGEMENT [5], [11], [12]

\begin{tabular}{|c|c|c|c|c|}
\hline Audit Point & Audit Domain & Activity & Remarks & Remarks \\
\hline $\begin{array}{l}\text { Launch/ } \\
\text { Plan }\end{array}$ & & $\begin{array}{l}\text { Establishing plans for change } \\
\text { management }\end{array}$ & $\begin{array}{l}\text { Analyzing the interested parties, planning scrum/agile education training, assigning } \\
\text { change management, and other planning }\end{array}$ & Additional \\
\hline $\begin{array}{l}\text { Execution/ } \\
\text { Regulation }\end{array}$ & $\begin{array}{l}\text { Change } \\
\text { Management }\end{array}$ & $\begin{array}{l}\text { Performing change } \\
\text { management }\end{array}$ & $\begin{array}{l}\text { Distinguishing/eliminating organizational obstacles according to the environment of } \\
\text { Agile development and performing programmatic change management }\end{array}$ & Additional \\
\hline Termination & & $\begin{array}{l}\text { Evaluating effectiveness and } \\
\text { performance of business }\end{array}$ & Measuring the team performance according to the Agile project measuring index & Additional \\
\hline
\end{tabular}

\section{2) Audit domain}

System architecture, applied system, and database apply the audit domain of the current information system audit model equally. However, the domain of change management, which is deduced from Agile process, was applied additionally. Audit points are classified into launch/plan, execution/regulation, and termination, and this classification is similar to the project management domain. On the other hand, change management activities are divided into establishing plans for change management, performing change management, and evaluating effectiveness and performance of the business.

\section{3) Audit viewpoint}

Procedures and products can be applied with the same standard as the information system audit standard. Business accomplishment has added productivity to reflect Agile characteristics. Agile cooperate by a self organizational project team and communicate continuously with customers. This team creates successful products in each sprint. They self-reflect on each sprint by repetitive plan, tracing, and evaluating the team speed, and also prepare for the next sprint.
The productivity is one of the important factors in business because it enables to predict the developer, scrum team, and release date of the final product beforehand [5]. Inspection standards according to audit viewpoints are listed below.

\section{B. Agile Methodology Audit Checkitems}

Basic check items were applied with Agile characteristics based on the current audit check items. The existing requirement analysis was named as requirement definition for the audit time, and the basic check items were applied. However, basic check items were moved to carry out the plan of an early unit/integrated test because it is important to do an early test for the Agile project. The requirements were analyzed, and release planning was added to establish release planning and repetitive plan. Moreover, basic check items, which were previously divided into analysis, design, and implementation, were integrated into architecture / construction. This process simplified check items and allowed the quality inspection of Agile project, by which analysis, design, and development run parallel to each other. Table $\mathrm{V}$ proposes the basic check items of applied system domain as below. 
TABLE IV: AUdiT VIEWPOINT AND INSPeCtion STANDARD OF THE AgILE MOdEL [5], [8]

\begin{tabular}{|c|c|c|c|}
\hline Audit Viewpoint & Inspection Standard & Related characteristics & Remarks \\
\hline \multirow{3}{*}{ Process } & Plan Reasonability & $\begin{array}{l}\text { Business management planning construction/management, evaluation of } \\
\text { suitability of establishing and following procedures }\end{array}$ & Existing \\
\hline & $\begin{array}{l}\text { Process } \\
\text { Reasonability }\end{array}$ & $\begin{array}{l}\text { Establishing development/management/maintenance procedure and reasonable } \\
\text { establishment of risk/schedule/quality/form/human resources/change } \\
\text { management procedures }\end{array}$ & existing \\
\hline & Compliance & $\begin{array}{l}\text { Following plans and risk / schedule / quality / form / human resources / change } \\
\text { management procedures fairly }\end{array}$ & Existing \\
\hline \multirow{7}{*}{ Product } & Functionality & $\begin{array}{l}\text { Sufficiency, completeness, accuracy, interoperability, and connectivity of the } \\
\text { Functionality function }\end{array}$ & Existing \\
\hline & Integrity & Data integrity and accuracy & Existing \\
\hline & Usability & User convenience, management convenience, and learning & Existing \\
\hline & Stability & System stability, service continuity, quick restoration & Existing \\
\hline & Efficiency & $\begin{array}{l}\text { Efficiency of using information resources (human resources, server, etc), work } \\
\text { efficiency, quick answers, system extendability, technology development } \\
\text { compatibility }\end{array}$ & Existing \\
\hline & Compliance & Following criteria / procedure / standard / methodology of the product & Existing \\
\hline & Consistency & Analysis, alteration, existing, traceability, maintainability & existing \\
\hline \multirow{3}{*}{ Performance } & Sufficiency & $\begin{array}{l}\text { Satisfaction of work/technical requirements, achieving performance goals, } \\
\text { sufficient task scope }\end{array}$ & Existing \\
\hline & Realizability & $\begin{array}{l}\text { Concreteness, feasibility, efficiency of investment, achieving the performance } \\
\text { goals, system availability }\end{array}$ & Existing \\
\hline & Productivity & $\begin{array}{l}\text { Speed and receptiveness of Agile, frequency of release and repetition, test } \\
\text { productivity, business accomplishment and productivity }\end{array}$ & Additional \\
\hline
\end{tabular}

TABLE V: BASIC CHECK ITEM OF APpliCATION SySTEM DOMAIN OF AgILE METHOdOLOGy Audit [8], [11], [12]

\begin{tabular}{|c|c|c|}
\hline Audit Point & Basic Check Items & Remarks \\
\hline \multirow{6}{*}{ Requirement Definition } & 01. Analyzing current work and checking whether possible solutions to the problem are proposed or not. & Existing \\
\hline & 02. Sufficiency and adequacy of deducing and analyzing users' requirements & Existing \\
\hline & 03. Adequacy of use-case model specification level about system function & Existing \\
\hline & 04. Checking whether conceptual analysis class was deduced sufficiently & Existing \\
\hline & 05. Checking whether user interface prototyping plan was set fairly & Existing \\
\hline & 06. Checking whether test plan was set appropriately & Change \\
\hline \multirow{2}{*}{ Release Plan } & 01. Checking whether release planning was set appropriately by analyzing requirements & Additional \\
\hline & 02. Setting repetitive plan and appropriate selection of story for the release & Additional \\
\hline \multirow{10}{*}{$\begin{array}{l}\text { Architecture/ } \\
\text { Construction }\end{array}$} & 01. Sufficiency and completeness of work and detailed analysis of user's requirement/design/implementation of functions & Change \\
\hline & 02. Sufficient refinement of use-case model & Existing \\
\hline & 03. Appropriate performance of user interface prototyping & Existing \\
\hline & 04. Designing for convenience of user interface and its report & Change \\
\hline & 05. Sufficiency and appropriateness of refining analysis class and designing class in details & Change \\
\hline & 06. Sufficiency and appropriateness of interior /exterior interface analysis/design/implement & Change \\
\hline & 07. Appropriate analysis/design/implement of access privileges and control & Change \\
\hline & 08. Detailed design for introducing/implementing the component & Change \\
\hline & 09. Unit testing & Existing \\
\hline & 10. Sprint review for each sprint & New \\
\hline
\end{tabular}

\section{Verification of the Agile Methodology Audit MODEL}

The survey about the necessity, audit time, and audit domain of the Agile methodology audit model was conducted (see Table VI). Ninety-six to hundred percent of the results indicated that Agile applied projects are needed.

The survey about the appropriateness of check lists indicates that basic check lists for the applied system is hundred percent suitable. Change management was 89.3 percent suitable, and Agile product detailed review items are 


\section{5 percent suitable (see Table VII).}

TABLE VI: ThE NeCESSITY FOR AUdit OF THE AIgLE METHOdOLOGY PROJECT

\begin{tabular}{|l|c|c|}
\hline \multicolumn{1}{|c|}{ Classification } & Yes & No \\
\hline Necessity of Agile applied projects & $100 \%$ & $0 \%$ \\
\hline Suitability of the audit time & $100 \%$ & $0 \%$ \\
\hline Necessity of adding the change management domain & $96.4 \%$ & $3.6 \%$ \\
\hline $\begin{array}{l}\text { Contribution of quality improvement during the audit, } \\
\text { which is suitable to Agile methodology applied projects }\end{array}$ & $100 \%$ & $0 \%$ \\
\hline
\end{tabular}

TABLE VII: A COMPLETE LIST OF THE SUITABILITY OF AGILE METHODOLOGY AUDIT CHECKLIST

\begin{tabular}{|l|c|c|c|c|}
\hline Classification & Items & Suitable & Average & $\begin{array}{l}\text { Not } \\
\text { Suitable }\end{array}$ \\
\hline Basic check lists of the Applied System & 10 & $100 \%$ & $0 \%$ & $0 \%$ \\
\hline $\begin{array}{l}\text { Basic check lists of change } \\
\text { management }\end{array}$ & 7 & $89.3 \%$ & $8.2 \%$ & $0 \%$ \\
\hline Review lists of Agile products & 20 & $99.5 \%$ & $0.5 \%$ & $0 \%$ \\
\hline
\end{tabular}

\section{Conclusions}

This paper proposes the audit model that perfectly fits to Agile characteristics by comparatively analyzing Agile methodology, which is currently applied in South Korea, and the current audit model. Audit time is when release and repetitive planning are established by analyzing a project-specific repetitive period and its form. When repetition is terminated and reviewed, audit is performed and a reinforcement of constant audit is required additionally. Audit check lists were formed throughout analysis, design, and development stages and added detailed review lists of major Agile products. It also reflected on check lists that reviews whether change management is practiced in Agile environment or not.

A proposed Agile methodology audit model in this paper will contribute greatly to performing audit in future. This research offers Agile methodology audit model based on a comparative analysis between a large IT organization's Agile methodology and the current audit model.

It is expected that combined strengths of Agile and various forms of methodologies will be applied and evolve together. Furthermore, information system audit should be studied continuously in order to take a prompt action in a complex environment.

\section{REFERENCES}

[1] H. Eriksson et al., UML2 toolkit., Indianapolis, USA: Wiley Publishing Inc, 2004.

[2] S. Bennett, S. McRobb, and R. Farmer, Object oriented systems analysis and design using UML, $2^{\text {nd }}$ ed., Berkshire, UK: MCGraw-Hill Inc., 2002.

[3] I. Sommerville, Software engineering. $7^{\text {th }}$ ed., Essex, England: Person Education Limited, 2004.

[4] H. Holmstrom et al., "Agile practices reduces distance in global software development," Information System Management, vol. 23, pp. $7-18,2006$

[5] H. Jegal, J. Lee, and T. Kim, Scaling software agility: best practices for large enterprises, Euiwang, Korea: Euiwang Publishing Inc., 2008.

[6] K. Henrik, W. Sim, W. Eum, and J. Han, Scrum and XP from the trenches., Insight, Korea: Insight, 2009.

[7] C. Kang, "A Study of Comment-oriented Documentation for Agile Software Development Method," M.S. thesis, School of Information System, Seogang Univ., Seoul, 2006.

[8] Korea National Information Society Agency, Information System Audit Guideline Manual V3.0- 2008.
[9] Korea National Information Society Agency, Information System Audit Guideline V1.0- 2009.

[10] Korea Ministry of Public Administration and Security, Information System Audit Guideline Revision Manual- 2010.

[11] A company, Agile Process Definition Documentation V1.1- 2011.

[12] B company, Audit Report for Information System Construction-2011.

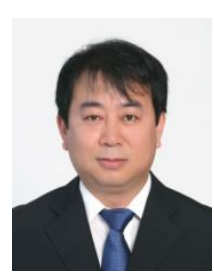

Dong Hyup Kim received his M.S. degree in Information System Audit from Konkuk University, Korea in 2012. He received his BS degree in Computer Engineering from Kangneung University, Kangwon, Korea in 1995.

$\mathrm{He}$ worked as a team manager at the Daegyo Company. Now he is a top manager in the department of Delivery Innovation Center at Samsung SDS, Seoul, Korea. His research interest includes Information System Audit, IT Outsourcing, Enterprise Architecture, and DB Security.

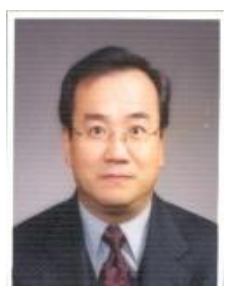

Dong Soo Kim received his $\mathrm{Ph} . \mathrm{D}$. degree in Management Information System from Kookmin University, Korea in 2005. He received his MS degree in Computer Science from Seoul National University of Science and Technology, Seoul, Korea in 2001. He also received his BS degree in Computer Science from Kwangwoon University, Seoul, Korea in 1981 $\mathrm{He}$ has three Certificate as a Professional Engineer(P.E.) in Information Systems Management, Computer Application System, and Computer Communications from the Korean Ministry of Science and Technology. He also has a Certificate as a Chief Information System Auditor from the Korean Ministry of Science and Technology.

He is a chief consultant in the department of Information System Audit at Korea Information System Audit \& Consulting (KISAC) Company and an adjunct professor at Graduate School of Information and Communications, Konkuk University, Seoul, Korea. He has published research papers in Information System Audit in the journal of Korea Digital Policy and Management. His research interest includes U-City Audit, Information System Audit, DB Quality, IT Outsourcing, Enterprise Architecture, and DB Security.

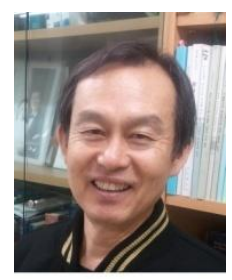

Chan Koh was born in Euisung, Korea. His first Ph.D. is in Electronic Engineering fron Kyunghee University, Seoul, Korea in 1991 and his second Ph.D is in Economics from Seoul National University, Seoul, Korea in 2008. He also has a MS in Computer Science from Yonsei University, Seoul, Korea in 1983, and a BS in Mechanical Engineering from Kyunghee University, Seoul, Korea in 1974. He has a Certificate as a Professional Engineer(P.E.) in Information Systems Management from the Korean Ministry of Science and Technology in 1987.

He served in the R.O.K Navy officer for three years as a systems analyst at R.O.K. Navy Command \& Staff College. Now, He is a professor in the department of Computer Science \& Engineering at Seoul National University of Science and Technology (SeoulTech), Seoul, Korea. Also, he is a Professor of Culture Policy Program, Graduate School of IT Policy at SeoulTech. He has been teaching courses at Helsinki Metropolia University of Applied Science in Finand since 2005. He has published research papers in IT convergence in the journal of Korea Digital Policy and Management. His research interest includes Computer Graphics, Game Design, Culture Technology, Cultural Policy and Management.

Dr. Koh is a vice president in the Society of Korea Digital Policy and Management, a director in the Society of Korea Digital Content, a director in the Society of Convergence Knowledge, sn editorial staff in the Korean Association for Regional Information Society.

Hee Wan Kim received his MS and Ph.D. degrees in Computer Engineering from Sungkyunkwan University, Seoul, Korea in 1995 and 2002. He received his B.S. degree in Computer Science from Kwangwoon University, Seoul, Korea in 1987. He has two Certificate as a Professional Engineer(P.E.) in Information Systems Management and a Chief Information System from the Korean Ministry of Science and Technology in 1995 and 2001.

He worked as a computer programmer for 4 years at Korea Electric Power Cooperation (KEPCO). Now, he is a professor in the division of Computer Science \& Engineering at Shamyook University, Seoul, Korea. He has published research papers in Information System Audit in the journal of Korea Digital Policy and Management. His research interest includes Database, Information System Audit, Project Management, and Software Engineering. He is an editorial staff in the Korean Association for IT Service Society. 